\title{
Thermal expansion of wood and timber-concrete composite members under ISO-fire exposure
}

\author{
ANDREA FRANGI and MARIO FONTANA \\ Institute of Structural Engineering, ETH Zurich, Switzerland
}

\section{Summary}

This paper discusses the influence and effects of thermal expansion on the structural behaviour of timber slabs and timber-concrete composite slabs exposed to ISO-fire. The first part of the paper presents a simplified model to calculate the effects of the thermal expansion, in the second part the calculation model is compared to fire test results.

\section{Keywords}

Thermal expansion, wood members under ISO-fire exposure, timber-concrete composite slabs, calculation model for fire

\section{Introduction}

A research project was carried out at the ETH on the fire behaviour of timber slabs made of hollow elements and timber-concrete composite slabs, which consist of timber members in the tensile zone, a thin concrete layer in the compression zone and the shear connection between timber and concrete. In a series of small-scale tests the fire behaviour of the connectors and the separating elements was experimentally analysed. A series of fire tests on slabs looked at the global structural behaviour of the timber slabs and timberconcrete composite slabs. All fire tests were based on ISO-fire exposure and performed at the Swiss Federal Laboratories for Materials Testing and Research in Dübendorf. Detailed experimental results of all fire tests are described in [5] and [6]. The design models developed for the calculation of the fire resistance of timber slabs and timberconcrete composite slabs is presented in [7].

The fire tests permitted the study of the influence and effects of thermal expansion on the structural behaviour of timber slabs and timber-concrete composite slabs. First a simplified model to calculate the effects of the thermal expansion is presented, its results are then compared to the fire tests.

\section{Calculation model}

The influence and effects of thermal expansion on the structural behaviour of timber slabs and timber-concrete composite slabs exposed to ISO-fire was studied using a linear elastic calculation model. The calculation model was applied to the tested slabs using the following basic assumptions:

- linear elastic material behaviour

- Bernoulli's hypothesis is valid also in the fire situation

- simply supported member (statically determinate system) subjected to thermal and mechanical actions 
- ISO-fire exposure as thermal action producing the same temperature field on each section along the member

- uniformly distributed loads and/or concentrated loads as mechanical actions producing only bending moments $\mathrm{M}$ (no axial forces $\mathrm{N}$ )

The geometries of the tested hollow core timber slabs and of the timber-concrete slab with a wood section made of timber planks are shown in Fig. 4. The timber slabs and the timber-concrete composite slab were exposed to ISO-fire on one side.

\section{Calculation model}

The cross-section of the structure is divided into $n$ hypothetical longitudinal unconnected layers (see Fig. 1a) with different stiffness and strength properties as a function of temperature $\Theta_{\mathrm{i}}(\mathrm{t})$. The temperature of each layer depends on the considered fire time and the section geometry.

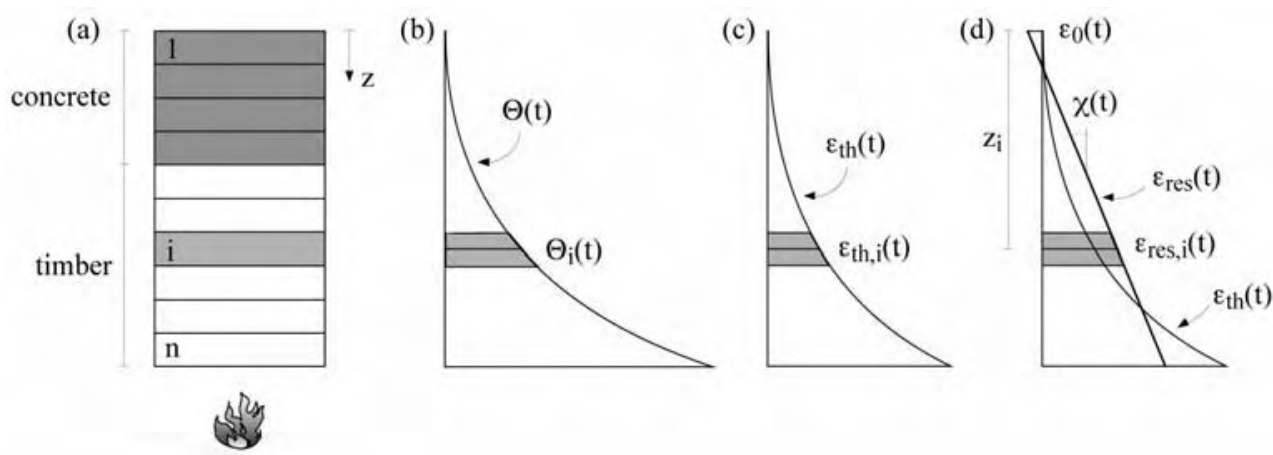

Figure 1 Calculation model: (a) cross-section composed of different layers, (b) temperature gradient of the cross-section, (c) thermal strains $\varepsilon_{\mathrm{th}, \mathrm{i}}$, (d) resulting strains $\varepsilon_{\text {res,i }}$

Because of the good insulating behaviour of charred and uncharred wood, typical temperature profiles through wood members exposed to fire exhibit a steep temperature gradient as presented in Fig. 1b. The steep temperature gradient will induce thermal strains $\varepsilon_{\mathrm{th}, \mathrm{i}}$, which are not linearly distributed (see Fig. 1c). The thermal strains $\varepsilon_{\mathrm{th}, \mathrm{i}}$ are calculated taking into account the coefficient of thermal expansion $\alpha_{T}$ as:

$$
\varepsilon_{\mathrm{th}, \mathrm{i}}(\mathrm{t})=\alpha_{\mathrm{T}} \cdot \Delta \Theta_{\mathrm{i}}(\mathrm{t})
$$

To fulfil the hypothesis of Bernoulli-Navier of a plane section, internal strains $\varepsilon_{\mathrm{E}, \mathrm{i}}$ producing residual thermal stresses $\sigma_{\mathrm{E}, \mathrm{i}}$ must be introduced. The total strains $\varepsilon_{\mathrm{res}, \mathrm{i}}$ resulting from the thermal strains $\varepsilon_{\mathrm{th}, \mathrm{i}}$ and the internal strains $\varepsilon_{\mathrm{E}, \mathrm{i}}$ may be calculated taking into account the strain of the upper layer $\varepsilon_{0}$ and the curvature $\chi$ of the cross-section as (see Fig. 1d):

$$
\varepsilon_{\text {res }, \mathrm{i}}(\mathrm{t})=\varepsilon_{\mathrm{th}, \mathrm{i}}(\mathrm{t})+\varepsilon_{\mathrm{E}, \mathrm{i}}(\mathrm{t})=\varepsilon_{0}(\mathrm{t})+\chi(\mathrm{t}) \cdot \mathrm{z}_{\mathrm{i}}(\mathrm{t})
$$


Therefore the internal strains $\varepsilon_{\mathrm{E}, \mathrm{i}}$ and the residual thermal stresses $\sigma_{\mathrm{E}, \mathrm{i}}$ may be calculated in function of $\varepsilon_{0}$ and $\chi$ as:

$$
\begin{aligned}
& \varepsilon_{E, i}(t)=\varepsilon_{r e s, i}(t)-\varepsilon_{t h, i}(t)=\varepsilon_{0}(t)+\chi(t) \cdot z_{i}(t)-\varepsilon_{t h, i}(t) \\
& \sigma_{E, i}(t)=E_{i}\left(\Theta_{i}\right) \cdot \varepsilon_{E, i}(t)=E_{i}\left(\Theta_{i}\right) \cdot\left[\varepsilon_{0}(t)+\chi(t) \cdot z_{i}(t)-\varepsilon_{t h, i}(t)\right]
\end{aligned}
$$

For a simply supported member which is not subjected to external loads, the thermal action does not produce external bending moments $\mathrm{M}$ and external axial forces $\mathrm{N}$. Therefore the strain of the upper layer $\varepsilon_{0}$ and the curvature $\chi$ of the cross-section can be found from static equilibrium requiring that the internal bending moment force $\mathrm{M}_{\Theta}$ and internal axial force $\mathrm{N}_{\Theta}$ due to the residual thermal stresses $\sigma_{\mathrm{E}, \mathrm{i}}$ must be zero:

$$
\begin{aligned}
& N_{\Theta}(t)=\sum_{i=1}^{n} \sigma_{E, i}(t) \cdot A_{i}=0 \\
& M_{\Theta}(t)=\sum_{i=1}^{n} \sigma_{E, i}(t) \cdot A_{i} \cdot z_{i}(t)=0
\end{aligned}
$$

The solutions of equations 5 and 6 are:

$$
\begin{aligned}
& \varepsilon_{0}(\mathrm{t})=\frac{\left(\Sigma \varepsilon_{\mathrm{th}, \mathrm{i}} \cdot \mathrm{EA}_{\mathrm{i}}\right) \cdot\left(\Sigma \mathrm{EA}_{\mathrm{i}} \cdot \mathrm{z}_{\mathrm{i}}^{2}\right)-\left(\Sigma \mathrm{EA}_{\mathrm{i}} \cdot \mathrm{z}_{\mathrm{i}}\right) \cdot\left(\Sigma \varepsilon_{\mathrm{th}, \mathrm{i}} \cdot \mathrm{EA}_{\mathrm{i}} \cdot \mathrm{z}_{\mathrm{i}}\right)}{\left(\Sigma \mathrm{EA}_{\mathrm{i}}\right) \cdot\left(\Sigma \mathrm{EA}_{\mathrm{i}} \cdot \mathrm{z}_{\mathrm{i}}^{2}\right)-\left(\Sigma \mathrm{EA}_{\mathrm{i}} \cdot \mathrm{z}_{\mathrm{i}}\right)^{2}} \\
& \chi(\mathrm{t})=\frac{\left(\Sigma \mathrm{EA}_{\mathrm{i}}\right) \cdot\left(\Sigma \varepsilon_{\mathrm{th}, \mathrm{i}} \cdot \mathrm{EA}_{\mathrm{i}} \cdot \mathrm{z}_{\mathrm{i}}\right)-\left(\Sigma \varepsilon_{\mathrm{th}, \mathrm{i}} \cdot \mathrm{EA}_{\mathrm{i}}\right) \cdot\left(\Sigma \mathrm{EA}_{\mathrm{i}} \cdot \mathrm{z}_{\mathrm{i}}\right)}{\left(\Sigma \mathrm{EA}_{\mathrm{i}}\right) \cdot\left(\Sigma \mathrm{EA}_{\mathrm{i}} \cdot \mathrm{z}_{\mathrm{i}}^{2}\right)-\left(\Sigma \mathrm{EA}_{\mathrm{i}} \cdot \mathrm{z}_{\mathrm{i}}\right)^{2}}
\end{aligned}
$$

The deflection w due to the curvature $\chi$ of the cross-section is calculated according to the principle of virtual work (see Fig. 2) as:

$$
\mathrm{w}(\mathrm{t})=\int_{0}^{\ell} \overline{\mathrm{M}}(\mathrm{x}) \cdot \chi(\mathrm{t}) \cdot \mathrm{dx}=\frac{1}{2} \cdot \chi(\mathrm{t}) \cdot \frac{\ell}{4} \cdot \ell=\frac{\chi(\mathrm{t}) \cdot \ell^{2}}{8}
$$
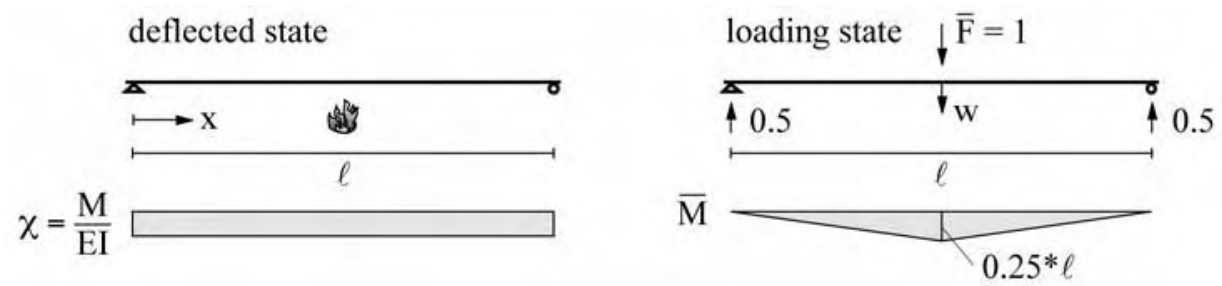

Figure 2 Model for the deflection for a simply supported beam exposed to fire only 
On the other hand, for a simply supported member which is subjected to external loads producing a bending moment $\mathrm{M}(\mathrm{x})$, the strain of the upper layer $\varepsilon_{0}$ and the curvature $\chi$ of the cross-section can be found from the conditions of equilibrium by:

$$
\begin{aligned}
& N_{\Theta}(t)=\sum_{i=1}^{n} \sigma_{E, i}(t) \cdot A_{i}=0 \\
& M_{\Theta}(t)=\sum_{i=1}^{n} \sigma_{E, i}(t) \cdot A_{i} \cdot z_{i}(t)=M(x)
\end{aligned}
$$

The solutions of the equations 10 and 11 are:

$$
\begin{aligned}
& \varepsilon_{0}(\mathrm{x}, \mathrm{t})=\frac{\left(\Sigma \varepsilon_{\mathrm{th}, \mathrm{i}} \cdot \mathrm{EA}_{\mathrm{i}}\right) \cdot\left(\Sigma \mathrm{EA}_{\mathrm{i}} \cdot \mathrm{z}_{\mathrm{i}}^{2}\right)-\left(\sum \mathrm{EA}_{\mathrm{i}} \cdot \mathrm{z}_{\mathrm{i}}\right) \cdot\left[\left(\sum \varepsilon_{\mathrm{th}, \mathrm{i}} \cdot \mathrm{EA}_{\mathrm{i}} \cdot \mathrm{z}_{\mathrm{i}}\right)+\mathrm{M}(\mathrm{x})\right]}{\left(\Sigma \mathrm{EA}_{\mathrm{i}}\right) \cdot\left(\Sigma \mathrm{EA}_{\mathrm{i}} \cdot \mathrm{z}_{\mathrm{i}}^{2}\right)-\left(\Sigma \mathrm{EA}_{\mathrm{i}} \cdot \mathrm{z}_{\mathrm{i}}\right)^{2}} \\
& \chi(\mathrm{x}, \mathrm{t})=\frac{\left(\Sigma \mathrm{EA}_{\mathrm{i}}\right) \cdot\left[\left(\Sigma \varepsilon_{\mathrm{th}, \mathrm{i}} \cdot \mathrm{EA}_{\mathrm{i}} \cdot \mathrm{z}_{\mathrm{i}}\right)+\mathrm{M}(\mathrm{x})\right]-\left(\Sigma \varepsilon_{\mathrm{th}, \mathrm{i}} \cdot \mathrm{EA}_{\mathrm{i}}\right) \cdot\left(\Sigma \mathrm{EA}_{\mathrm{i}} \cdot \mathrm{z}_{\mathrm{i}}\right)}{\left(\Sigma \mathrm{EA}_{\mathrm{i}}\right) \cdot\left(\Sigma \mathrm{EA}_{\mathrm{i}} \cdot \mathrm{z}_{\mathrm{i}}^{2}\right)-\left(\Sigma \mathrm{EA}_{\mathrm{i}} \cdot \mathrm{z}_{\mathrm{i}}\right)^{2}}
\end{aligned}
$$

The deflection w due to the curvature $\chi$ of the cross-section is calculated as:

$$
w(x, t)=\int_{0}^{\ell} \bar{M}(x) \cdot \frac{M}{E I}(x, t) \cdot d x=\int_{0}^{\ell} \bar{M}(x) \cdot \chi(x, t) \cdot d x
$$

\section{Material properties}

For the calculation of the influence and effects of thermal expansion on the structural behaviour of timber slabs and timber-concrete composite slabs exposed to ISO-fire, it is necessary to know the temperature development in the cross-section in function of time as well as the thermal and mechanical material properties such as coefficient of thermal expansion and modulus of elasticity of the different components of the structure (timber and concrete) in function of temperature.

The thermal expansion of timber may be calculated according to Christoph [1] as:

$$
\varepsilon_{\mathrm{th}, \mathrm{i}}=\Delta \ell / \ell=\alpha_{\mathrm{T}} \cdot \Delta \Theta_{\mathrm{i}}=4.0 \cdot 10^{-6} \cdot \Delta \Theta_{\mathrm{i}}
$$

The thermal expansion of concrete may be calculated according to ENV-1994-1-2 [3] as:

$$
\varepsilon_{\mathrm{th}, \mathrm{i}}=\Delta \ell / \ell=-1.8 \cdot 10^{-4}+9.0 \cdot 10^{-6} \cdot \Theta_{\mathrm{i}}+2.3 \cdot 10^{-11} \cdot \Theta_{\mathrm{i}}^{3}
$$

The steep temperature gradient of wood members exposed to ISO-fire can be described as a function of fire time and charring rate. From all temperatures measured during the ETH fire tests the following expression was developed for the calculation of the temperature profile in a wood member subjected to ISO-fire on one side [7]: 
$\Theta(x)=20+180 \cdot\left(\frac{\beta \cdot t}{x}\right)^{\alpha(t)}$

$\alpha(t)=0.025 \cdot t+1.75$

$\Theta: \quad$ temperature in ${ }^{\circ} \mathrm{C}$ in function of the depth $\mathrm{x}$

$\beta$ : $\quad$ charring rate in $\mathrm{mm} / \mathrm{min}$

$\mathrm{t}$ : fire time in minutes

$\mathrm{x}$ : depth measured from the surface of the cross-section in $\mathrm{mm}$

The charring rate $\beta$ is the main parameter to describe the process of thermal degradation (pyrolysis) of wood subjected to fire producing combustible gases, accompanied by a loss in weight and cross-section. The ETH fire tests performed with wood members exposed to ISO-fire of 30 up to 110 minutes demonstrated that a constant charring rate $\beta$ of about $0.7 \mathrm{~mm} / \mathrm{min}$ may be assumed.

Fire reduces the cross-section as well as the stiffness and strength properties in function of temperature. For the concrete slab, the temperature-dependent reduced stiffness and strength properties according to ENV-1994-1-2 [3] are considered in this study.
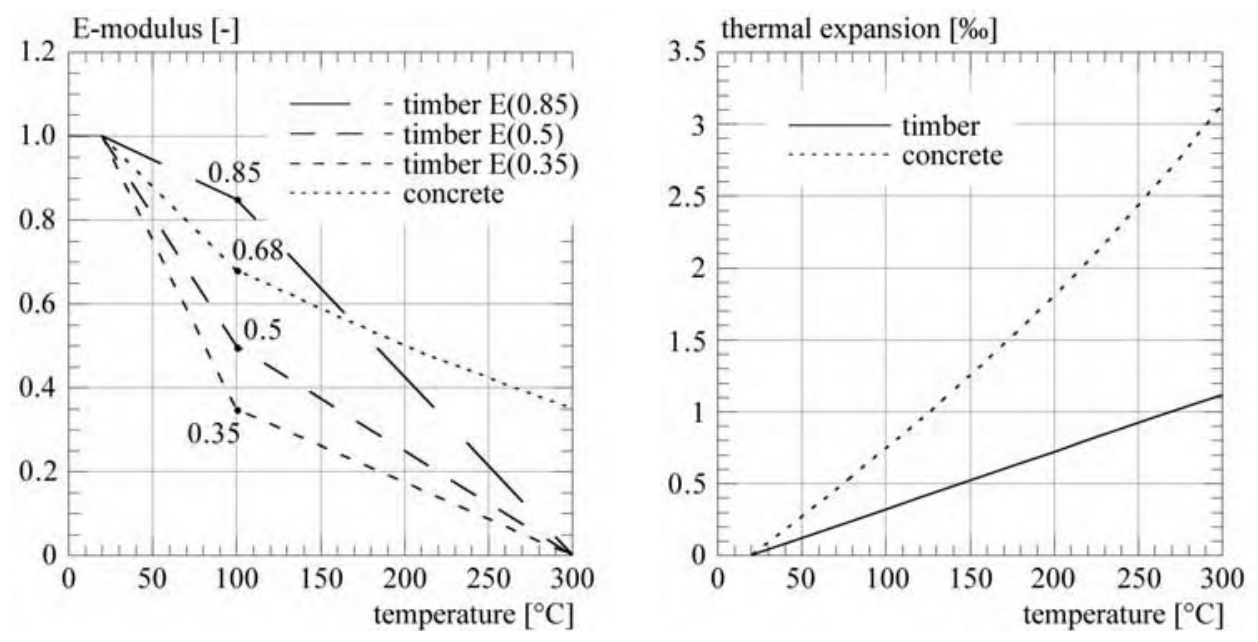

Figure 3 Thermal expansion and modulus of elasticity $\mathrm{E}$ of timber and concrete considered in this study in function of the temperature

For the temperature-dependent material properties of wood a large and often contradictory variation of values is given by different sources [11]. Glos [8] conducted tests on structural timber members of sizes used in practice in bending, compression and tension. The test specimens were heated to a constant temperature and then loaded to failure. The reduced modulus of elasticity obtained for bending is shown in Fig. 3 with $\mathrm{E}(0.85)$. König [10] conducted extensive experimental research on the fire behaviour of light timber frame assemblies. Especially the performance of timber frame members in bending at standard fire exposure was studied [9]. The fire tests were conducted such that the fire- 
exposed side was either in compression or tension. Thereby it was possible to separate the effect of temperature on the modulus of elasticity $\mathrm{E}$ in tension and compression. The reduced moduli of elasticity obtained are shown in Fig. 3 with $\mathrm{E}(0.5)$ for tension and $\mathrm{E}(0.35)$ for compression. They deviate considerably from those given by Glos with $\mathrm{E}(0.85)$. There are several reasons for this. One is that it is difficult to maintain a controlled level of moisture content during the tests. Another reason is the effect of loading rate: already considerable at normal temperature, it is much greater at elevated temperatures and sensitive to moisture.

Figure 3 shows the thermal and mechanical properties of timber and concrete in function of temperature, used for the following parametric study.

\section{Comparison with fire tests}

The calculated effects of thermal expansion are compared to results of bending tests performed with a timber-concrete composite slab and two timber slabs made of hollow core elements shown in Fig. 4. All slabs were exposed to ISO-fire from below.

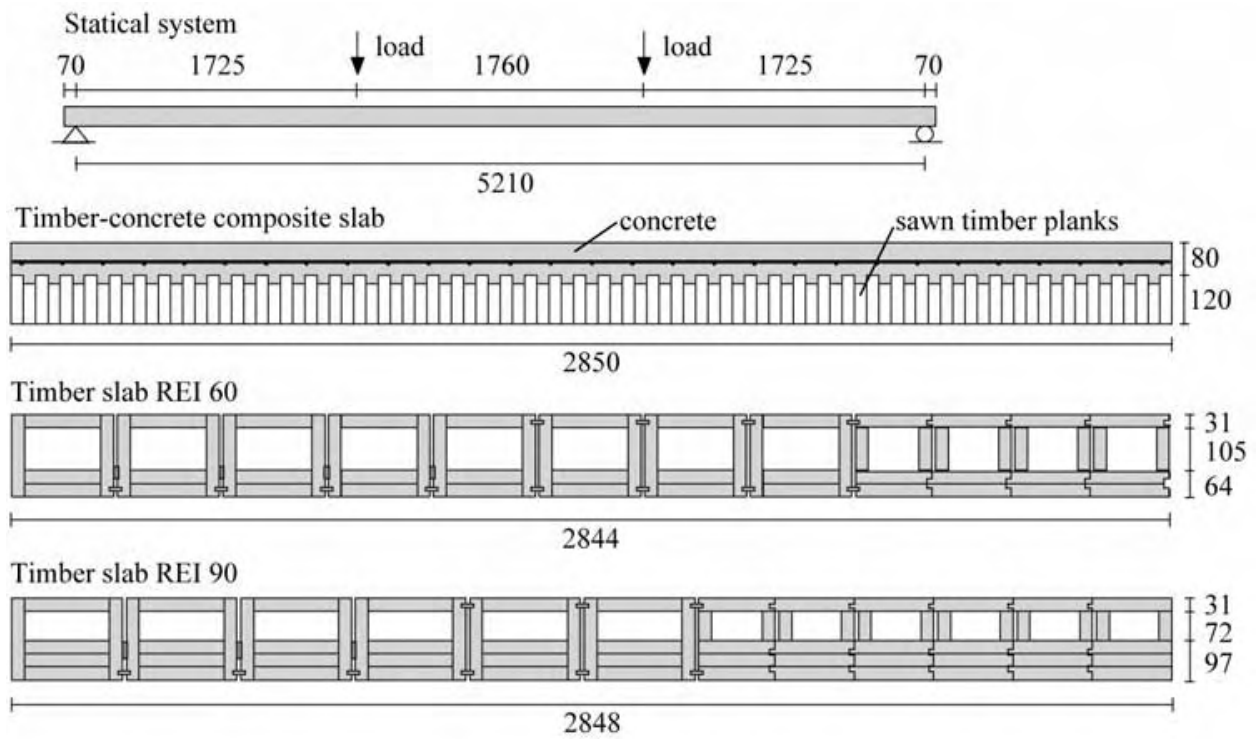

Figure 4 Cross-sections of the slabs exposed to ISO-fire

The timber-concrete composite slab consisted of sawn spruce timber planks 100 and 120 $\mathrm{mm}$ high and a 80 to $100 \mathrm{~mm}$ thick concrete layer (see Fig. 4). The composite slab had no connectors between the timber planks and the concrete layer. The shear connection between concrete and timber was realised by micro-mechanical interlock between concrete and the raw sawn surface of the timber planks with an alternating height of 100 and $120 \mathrm{~mm}$. The slab was loaded with hydraulic jacks positioned at about a third of the span. The load level $F_{\text {fire }}$ during the fire test was set in such a way that the maximum bending moment corresponded to that in a slab of $6.5 \mathrm{~m}$ span, with a permanent load of $1.5 \mathrm{kN} / \mathrm{m}^{2}$ and a reduced accompanying variable load of $0.3 * 3.0 \mathrm{kN} / \mathrm{m}^{2}$ allowing for a reduction of the variable load due to the low probability of coincidence of the maximum variable load and fire according to the Swiss action code SIA 160 [12]. The timber concrete composite 
slab, which showed no slip between concrete and timber during the test, was exposed to 90 minutes of ISO-fire.

The two timber slabs were made of $200 \mathrm{~mm}$ high hollow elements of spruce with a mean density of $450 \mathrm{~kg} / \mathrm{m}^{3}$. Two different types of slab with three different types of joint between the timber elements were designed for a fire resistance of 60 and 90 minutes (see Fig. 4). The load level during the fire tests was set in such a way that the maximum bending moment corresponded to that in a slab of about $7.10 \mathrm{~m}$ span, with a permanent load of $1.5 \mathrm{kN} / \mathrm{m}^{2}$ and a reduced accompanying live load of $0.5 * 3.0 \mathrm{kN} / \mathrm{m}^{2}$ according to ENV-1991-1 [2]. The timber slabs were exposed to 70 minutes and 105 minutes of ISOfire. No relevant smoke or flame penetration was observed through the three different types of joint between the timber elements.

In the fire tests the temperatures in selected locations, the vertical deflections and the horizontal deformations were measured. Detailed experimental results of the fire tests are described in [5] and [6].

\section{Influence of thermal expansion on the deflection}

Figure 5 compares the deflection measured during the fire tests with the deflection calculated in function of the three different cases for the temperature-dependent reduction of the modulus of elasticity E of timber as shown in Fig. 3. The assumed stiffness properties of the slabs at room temperature were calculated from the deflections measured before the fire tests. Figure 5 left illustrates the deflection $\mathrm{w}_{\text {th }}$ due to the influence of the thermal expansion $\alpha_{\mathrm{T}}$ according to equation 15 and the deflection $\mathrm{w}$ due to the external mechanical loads. Figure 5 right gives the total deflection $\mathrm{w}_{\mathrm{tot}}$. From Fig. 5 the following conclusions can be drawn:

- the sharp increase in the deflections measured at the beginning of the fire tests shows the influence of the thermal expansion of timber.

- the calculated deflections $\mathrm{w}$ due to the external mechanical loads depend strongly on the different material laws for the temperature-dependent reduction of the modulus of elasticity $\mathrm{E}$ of timber. Further it can be seen that the calculated deflections $\mathrm{w}$ are always smaller than the deflection measured during the fire tests. Therefore a calculation model, which does not consider the effects of thermal expansion, underestimates the deflections measured during the fire tests.

- the calculated deflections $\mathrm{w}_{\mathrm{th}}$ due to the influence of thermal expansion depend only slightly on the different cases for the temperature-dependent reduction of the modulus of elasticity $\mathrm{E}$ of timber. However the influence of thermal expansion leads to a considerable increase of the deflection during the fire tests.

- the calculated deflections $\mathrm{w}_{\text {tot }}$ which consider the effects of thermal expansion are in good agreement with the deflection measured during the fire tests. 

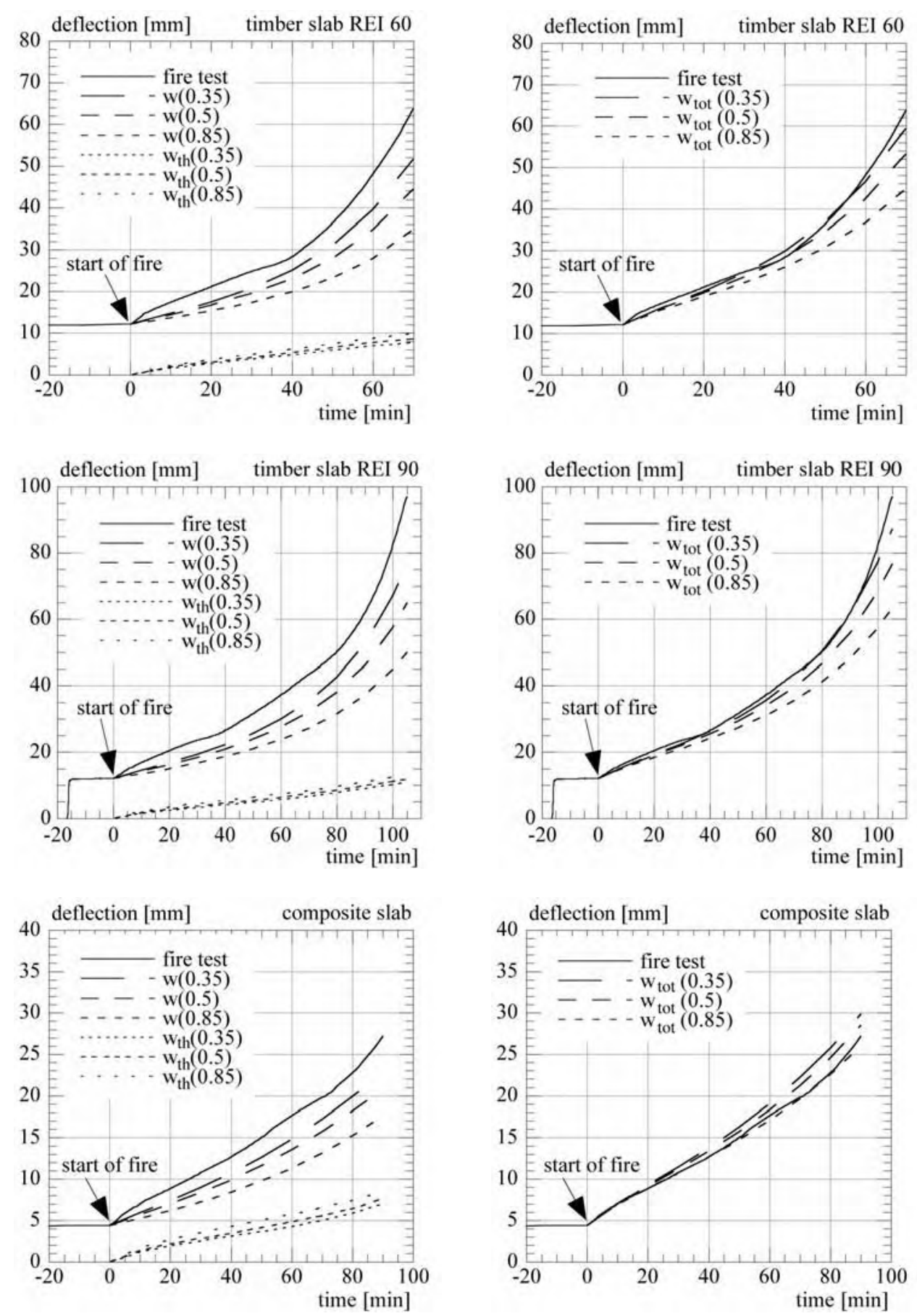

Figure 5 Comparison of calculated and measured deflections for different material laws according to Fig. 3 left and a charring rate of $0.7 \mathrm{~mm} / \mathrm{min}$. 

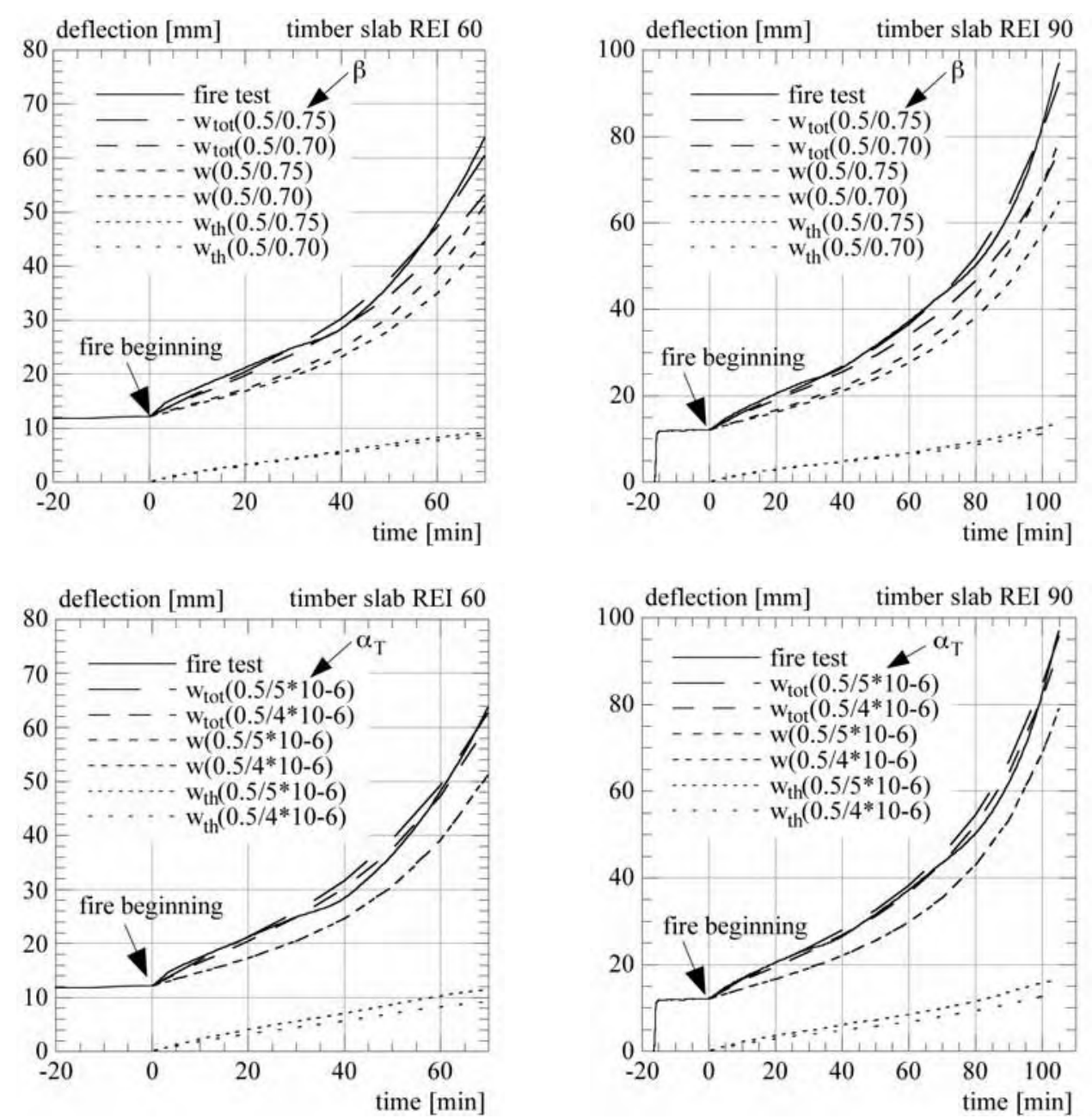

Figure 6 Influence of the assumed charring rate and thermal coefficient on the calculation model

Figure 6 illustrates the influence of the charring rate $\beta$ and thermal coefficient $\alpha_{\mathrm{T}}$ assumed for the calculation model. The deflection was calculated with a charring rate $\beta$ of $0.70 \mathrm{~mm} / \mathrm{min}$ or $0.75 \mathrm{~mm} / \mathrm{min}$ and a thermal coefficient $\alpha_{\mathrm{T}}$ of $4 * 10^{-6} \mathrm{~K}^{-1}$ or $5 * 10^{-6} \mathrm{~K}^{-1}$.

Figure 6 shows that:

- the assumed charring rate of timber has a considerable influence on the calculated deflections $w$ due to the external mechanical loads. On the other hand, the influence of the charring rate on the calculated deflections $\mathrm{w}_{\text {th }}$ due to thermal expansion is small.

- the calculated deflections $\mathrm{w}_{\text {th }}$ due to the influence of thermal expansion depend strongly on the assumed thermal coefficient $\alpha_{T}$ of timber. However, as the calculated deflection w due to the external mechanical loads is considerably higher than the calculated deflection $\mathrm{w}_{\mathrm{th}}$ due to the influence of thermal expansion, the influence of the assumed thermal coefficient $\alpha_{\mathrm{T}}$ of timber on the calculated total deflection $\mathrm{w}_{\text {tot }}$ is quite small. 
Figure 7 shows the residual thermal stresses due to the influence of thermal expansion calculated after 30, 60 and 90 minutes for the timber-concrete composite slab shown in Fig. 4. The residual thermal stresses were calculated in function of temperature-dependent reductions of the modulus of elasticity $\mathrm{E}$ of timber $\mathrm{E}(0.5)$ and $\mathrm{E}(0.85)$ as shown in Fig. 3.
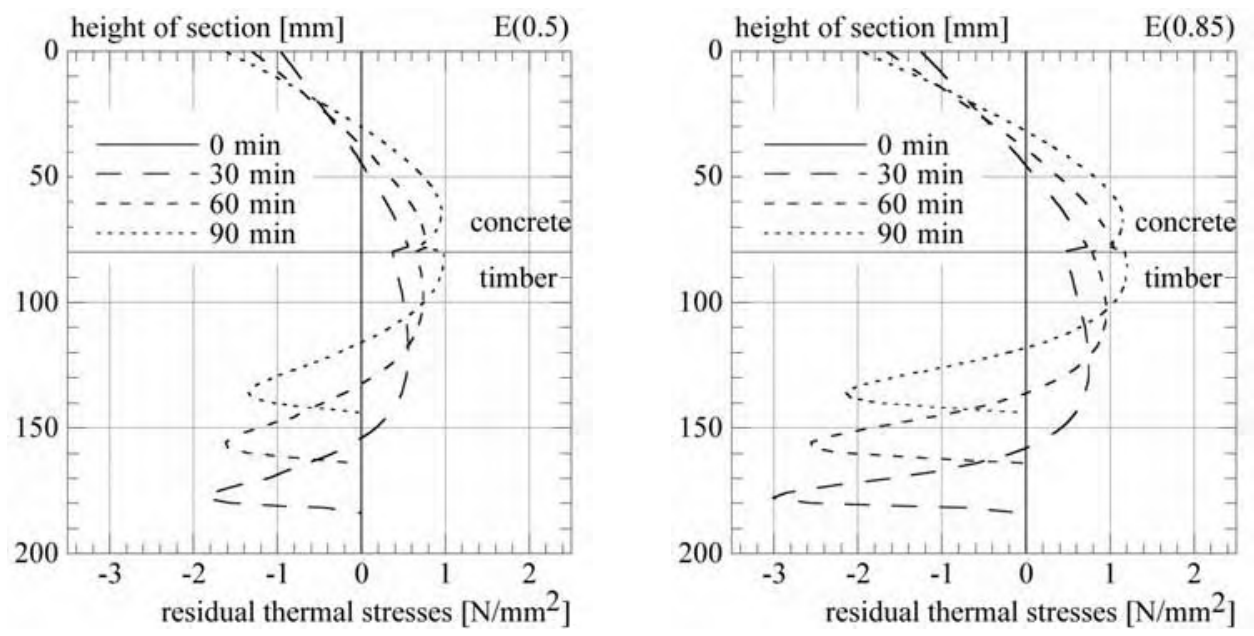

Figure 7 Residual thermal stresses due to the influence of the thermal expansion calculated after 30, 60 and 90 minutes for the timber-concrete composite slab

From Fig. 7 following conclusions can be drawn:

- the effect of thermal expansion leads to residual thermal compressive stresses in the upper and lower part of the cross-section and residual thermal tensile stresses in the middle part of the cross-section.

- the residual thermal compressive stresses slightly decrease with increasing fire time, while the residual thermal tensile stresses slightly increase.

- because of the thermal degradation of wood, the positions of the greatest compressive and tensile residual thermal stresses move towards the unexposed side of the crosssection with increasing fire time.

- the calculated residual thermal stresses are quite small. Further it can be seen that the residual thermal stresses $\sigma_{\mathrm{E}}$ calculated with $\mathrm{E}(0.85)$ are slightly greater than $\sigma_{\mathrm{E}}$ calculated with $\mathrm{E}(0.5)$. 

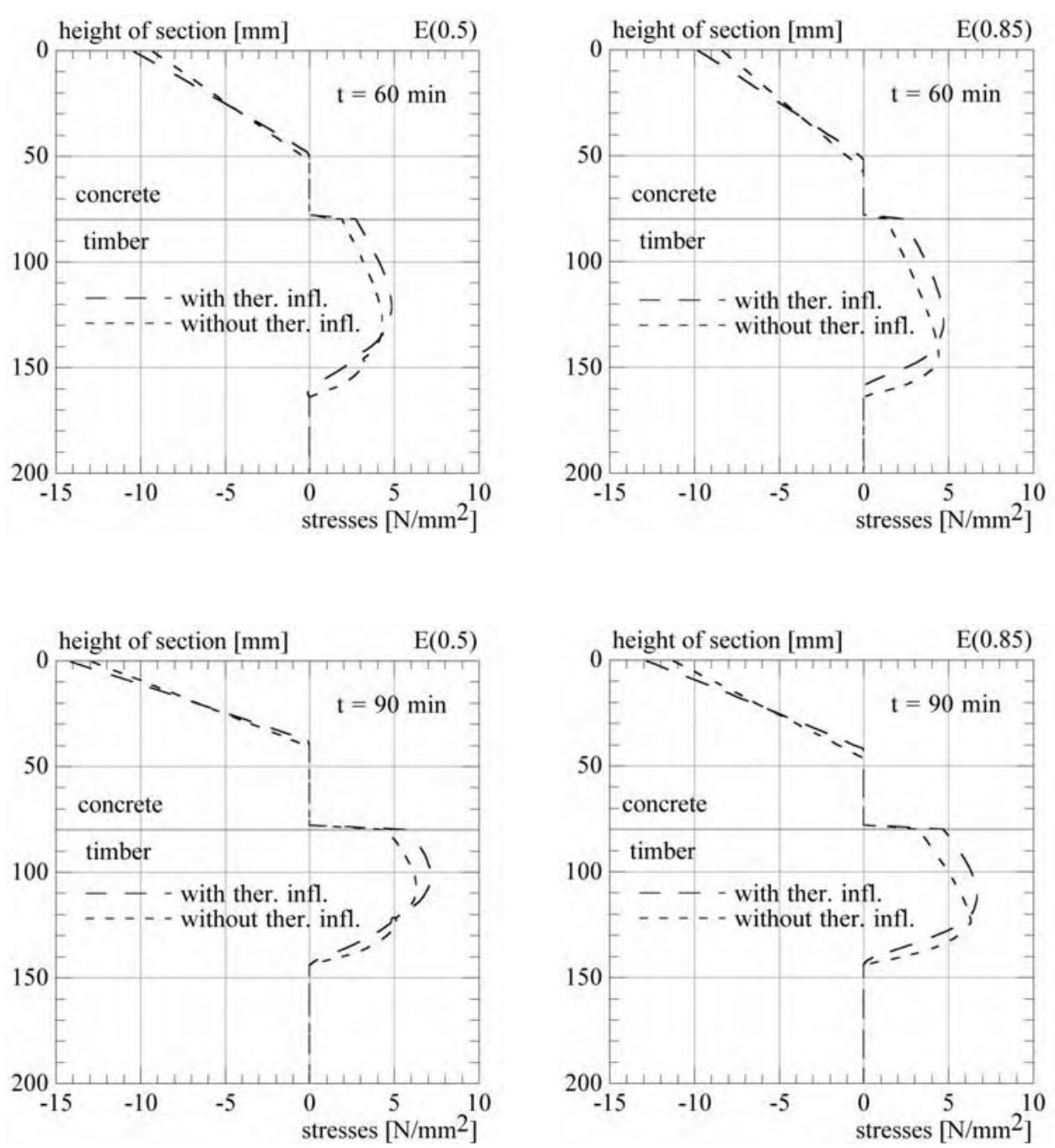

Figure 8 Resulting stresses calculated with and without the influence of the thermal expansion for the cross-section with the maximum bending moment due to the external mechanical loads

Figure 8 shows the resulting stresses calculated with and without the influence of thermal expansion for the cross-section subjected to the maximum bending moment due to the external mechanical loads. The resulting stresses were calculated after 60 and 90 minutes in function of the temperature-dependent reduction of the modulus of elasticity $\mathrm{E}$ of timber $\mathrm{E}(0.5)$ and $\mathrm{E}(0.85)$ as shown in Fig. 3. Figure 8 shows that the differences between the resulting stresses calculated with and without the influence of thermal expansion are quite small. For this reason, the fire resistance $t_{R}$ of a timber-concrete slab calculated considering the influence of thermal expansion differs by only few minutes from $t_{R}$ calculated without the influence of thermal expansion [7]. 


\section{Conclusions}

A research project was carried out at the ETH on the fire behaviour of timber slabs and timber-concrete composite slabs. The fire tests permitted studying the effects of thermal expansion on the structural behaviour of the slabs. The first part of the paper presented a simplified linear elastic model to calculate the effects of thermal expansion on deflections and stresses, in the second part this calculation model was compared to fire test results. From the study the following conclusions can be drawn:

- the effect of thermal expansion leads to an increase of the deflection. Therefore calculation models, which do not consider this influence, underestimate the deflection measured during fire tests.

- the effect of thermal expansion leads to residual thermal stresses. However, the calculation model showed that the residual thermal stresses are small in comparison to the stresses due to external mechanical loads and may therefore be neglected in the calculation of the fire resistance time of beams and slabs.

\section{References}

1. Christoph N., Brettel G., „Untersuchungen zur Wärmedehnung von Holz in Abhängigkeit von Rohdichte und Temperatur", Holz als Roh- und Werkstoff 35, 1977.

2. ENV 1991-1 (Eurocode 1), ,Basis of design and actions on structures - Part 1: Basis of design", CEN, Brussels, 1994.

3. ENV 1994-1-2 (Eurocode 4), „Design of composite steel and concrete structures Part 1-2: General rules - Structural fire design“", CEN, Brussels, 1995.

4. ENV 1995-1-2 (Eurocode 5), „Design of timber structures - Part 1-2: General rules - Structural fire design“, CEN, Brussels, 1994.

5. Frangi A., Fontana M., „Zum Brandverhalten von Holzdecken aus Hohlkastenelementen “, Institute of Structural Engineering (IBK). ETH Zurich, IBK Report No. 244, Birkhäuser Basle, 1999.

6. Frangi A., Fontana M., „Versuche zum Tragverhalten von Holz-Beton-Verbunddecken bei Raumtemperatur und Normbrandbedingungen", Institute of Structural Engineering, ETH Zurich, IBK Report No. 249, Birkhäuser Basle, 2000.

7. Frangi A., Fontana M., „Brandverhalten von Holz-Beton-Verbunddecken “, Institute of Structural Engineering, ETH Zurich, IBK Report No. 269, Birkhäuser Basle, 2001.

8. Glos P., Henrici D., „Festigkeit von Bauholz bei hohen Temperaturen“, Final report 87505, Institut für Holzforschung der Universität München, 1990.

9. König J., "Fire resistance of timber joists and load bearing wall frames", Swedish Institute for Wood Technology Research, Rapport I 9412071, Stockholm, 1995.

10. König J., Walleij L., "Timber frame assemblies exposed to standard and parametric fires. Part 2: a design model for standard fire exposure”, Swedish Institute for Wood Technology Research (Trätek), Rapport I 0001001, Stockholm, 2000.

11. König J., Källsner B., "Thermal and mechanical properties of timber and some other materials used in light timber frame construction", CIB-W18, Paper 33-16-3, Meeting 33, Delft, 2000.

12. SIA 160 (Code), ,Einwirkung auf Tragwerke“, Schweiz. Ingenieur- und Architektenverein, Zürich, 1989. 